\title{
CONDENSATION OF WATER VAPOR IN A VERTICAL TUBE CONDENSER
}

\author{
Jan HaVlik*, TOMAS DlOUhY
}

\author{
Department of Energy Engineering, Faculty of Mechanical Engineering, Czech Technical University in Prague \\ Technická 4, Praha 16607, Czech Republic \\ * corresponding author: jan.havlik@fs.cvut.cz
}

\begin{abstract}
This paper presents an analysis of heat transfer in the process of condensation of water vapor in a vertical shell-and-tube condenser. We analyze the use of the Nusselt model for calculating the condensation heat transfer coefficient (HTC) inside a vertical tube and the Kern, Bell-Delaware and Stream-flow analysis methods for calculating the shell-side HTC from tubes to cooling water. These methods are experimentally verified for a specific condenser of waste process vapor containing air. The operating conditions of the condenser may be different from the assumptions adopted in the basic Nusselt theory. Modifications to the Nusselt condensation model are theoretically analyzed.
\end{abstract}

KEYwoRDS: condensation; vertical tube condenser; heat transfer coefficient.

\section{INTRODUCTION}

Condensers are used in a range of chemical, petroleum, processing and power facilities for distillation, for refrigeration and for power generation. Most condensers used in the chemical process industries are water-cooled shell-and-tube exchangers and air-cooled tube or platen exchangers. Shell-and-tube condensers, which are used for condensing process vapors, are classified according to orientation (horizontal and vertical) and according to the placement of the condensing vapor (shell-side and tube-side) [1].

This paper deals with vertical shell-and-tube condensers with tube-side condensation. Calculations of the overall heat transfer coefficient necessary for the design of the condenser heat transfer area are well described in the literature, but for limited operating conditions only. The Nusselt condensation model, which is often recommended for calculating the condensing side HTC, is derived for conditions which need not be satisfied in real operation [2, 3. The methods by Kern, Bell-Delaware and the Stream-flow analysis method, which are commonly used for calculating the shell-side HTC, provide different values [1]. The first step in an analysis of the condensation process is to test these methods in operating conditions different from the assumptions adopted in the basic Nusselt theory. In the second step, the applicability of the methods will be proved, or modifications to them will be designed.

\section{VERTICAL TUBE-SIDE DOWNFLOW CONDENSER}

This configuration is often used in the chemical industry. It consists of a shell with fixed tubesheets. The lower head is over-sized to accommodate the condensate and a vent for non-condensable gases. The condensate flows down the tubes in the form of an annular film of liquid, thereby maintaining good contact with both the cooling surface and the remaining vapor. Disadvantages are that the coolant, which is often more prone to fouling, is on the shell side, and the use of finned tubes is precluded.

The overall heat transfer coefficient $U$ is given from the equation

$$
U=\frac{1 / D_{o}}{\frac{1}{d_{i} h_{c}}+\frac{1}{2 k} \ln \frac{D_{o}}{d_{i}}+\frac{1}{D_{o} h_{w}}}
$$

where $d_{i}$ is the inside diameter of the tubes, $h_{c}$ is the tube-side HTC (vapor condensation), $k$ is the thermal conductivity of the tubes, $D_{o}$ is the outside diameter of the tubes, and $h_{w}$ is the shell-side HTC.

\section{Nusselt THEORY OF CONDENSATION ON A VERTICAL SURFACE}

The basic heat-transfer model for film condensation was first derived by Nusselt to describe how a purecomponent saturated vapor condenses on a vertical wall, forming a thin film of condensate that flows downward due to gravity [2, 3]. The following assumptions are made:

(1.) The flow in the condensate film is laminar.

(2.) The temperature profile across the condensate film is linear. This assumption is reasonable for a very thin film.

(3.) Advection in the film is neglected.

(4.) The shear stress at the vapor-liquid interface is negligible.

(5.) The fluid velocity in the film is small.

(6.) The fluid properties are constant for the liquid film.

(7.) The wall is flat (no curvature). 
(8.) The system is in a steady state.

Then the following equation was introduced:

$$
h_{c}=\frac{2 \sqrt{2}}{3}\left(\frac{\varrho_{L} g\left(\varrho_{L}-\varrho_{p}\right) h_{f g}^{\prime} k_{L}^{3}}{\mu_{L} \Delta T_{s a t} L}\right)^{1 / 4} \text {, }
$$

where $\varrho_{L}$ is the density of the condensate, $\varrho_{p}$ is the density of the water vapor, $h_{f g}^{\prime}$ is the latent heat of condensation, $k_{L}$ is the thermal conductivity of the condensate, $\mu_{L}$ is the dynamic viscosity of condensate, $\Delta T_{\text {sat }}$ is the difference between the saturation temperature and the wall temperature, and $L$ is the wall length.

\section{SHELL-SIDE HTC}

The methods by Kern, by Bell-Delaware, and the Stream flow analysis method are widely used for calculating the shell-side HTC. Hewitt et al. 1] present these methods very well. These methods take into account the following factors, which are specific for shell-and-tube heat exchangers:

(1.) Tube layout and pitch

(2.) Effect of production clearance on temperature and velocity profiles

The tube layout and the pitch influence the coefficients in the resulting Equations (3), (6), (9) of the methods. Production clearances are included in the calculation by correction factors.

\subsection{The Kern method}

Based on data from industrial heat transfer operations and for a fixed baffle size ( $75 \%$ of the shell diameter), the following equation was introduced:

$$
h_{2}=\frac{k}{D_{e}} \cdot 0.36 \operatorname{Re}^{0.55} \operatorname{Pr}^{0.33}
$$

where $k$ is the fluid thermal conductivity and $D_{e}$ is the equivalent diameter defined in (5). No change in viscosity from the bulk to the wall is assumed. The Reynolds number Re is defined as

$$
\operatorname{Re}=\frac{m_{s}^{\prime} D_{e}}{\mu}
$$

where $m_{s}^{\prime}$ is the shell-side mass velocity calculated from the total mass flow in the shell $M_{T}^{\prime}$ and the cross-flow area at the diameter of the shell $S_{s}$ as $m_{s}^{\prime}=M_{T}^{\prime} / S_{s}$, the equivalent diameter $D_{e}$ is defined in the usual way as

$$
D_{e}=\frac{4 \cdot \text { flow area }}{\text { wetter perimeter }}
$$

and $\mu$ is the fluid dynamic viscosity.

\subsection{The Bell-Delaware method}

In this method, correction factors for the following elements were introduced:

(1.) Leakage through the gaps between the tubes and baffles, and between the baffles and the shell.

(2.) Bypassing of the flow around the gap between the tube bundle and the shell.

(3.) Effect of the baffle configuration (i. e., recognition of the fact that only a fraction of the tubes are in pure cross-flow).

(4.) Effect of the adverse temperature gradient on heat transfer in laminar flow.

The ideal cross-flow heat transfer coefficient is given by

$$
h_{c f}=\frac{k}{D_{o}} \cdot 0.273 \operatorname{Re}^{0.653} \operatorname{Pr}^{0.34}
$$

where the Reynolds number Re is defined as

$$
\operatorname{Re}=\frac{\varrho V_{\max } D_{o}}{\mu}
$$

where $\varrho$ is the fluid density, $V_{\max }$ is the maximum intertube velocity between tubes near the centerline of the flow [1] and $D_{o}$ is the external diameter of the tube. Then the shell side heat transfer coefficient is given by

$$
h_{w}=h_{c f} J_{C} J_{L} J_{B},
$$

where $J_{C}$ is the correction factor for the baffle configuration, $J_{L}$ is the correction factor for leakage, and $J_{B}$ is the correction factor for the bypass in the bundleshell gap [1].

\subsection{THE FLOW-STREAM ANALYSIS METHOD}

This method makes a detailed analysis of the flow in a heat exchanger. The fluid flows inside an exchanger via various routes. Leakage flows occur between the tubes and the baffle, and between the baffle and the shell. Part of the flow passes over the tubes in crossflow, and part bypasses the bundle. The cross-flow and bypass streams combine to form a further stream that passes through the window zone. A correction factor $F_{c r}$, which adjusts the mass flow calculation (the Reynolds number), takes these effects into account. Then the shell-side heat transfer coefficient is given by

$$
h_{w}=\frac{k}{D_{o}} \cdot 0.273 \operatorname{Re}_{c r}^{0.653} \operatorname{Pr}^{0.34},
$$

where $\operatorname{Re}_{c r}=F_{c r}$ Re. The Reynolds number Re is defined the same as in Section 4.2 according to (7).

Generally speaking, the Kern method offers the simplest route, the Bell-Delaware method is the most widely-accepted method, and Flow-stream analysis is the most realistic method. 


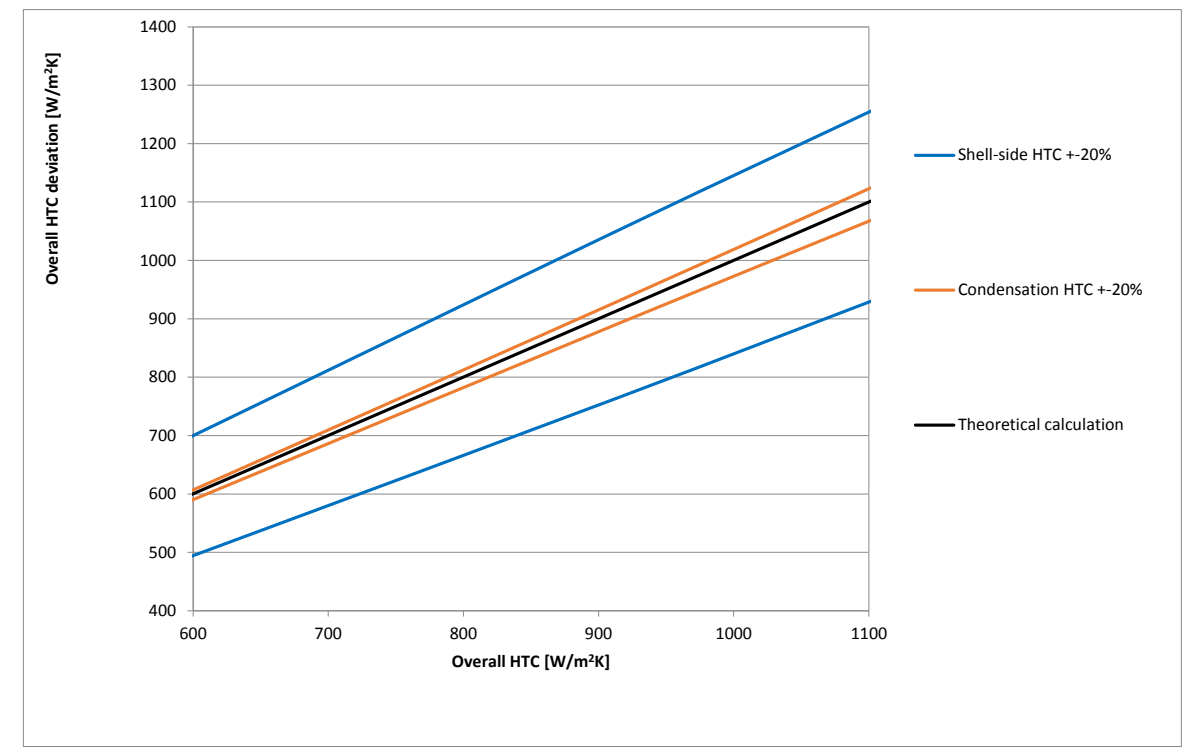

FiguRE 2. Impact of the accuracy of the shell-side determination and the tube-side HTC determination on the overall HTC.

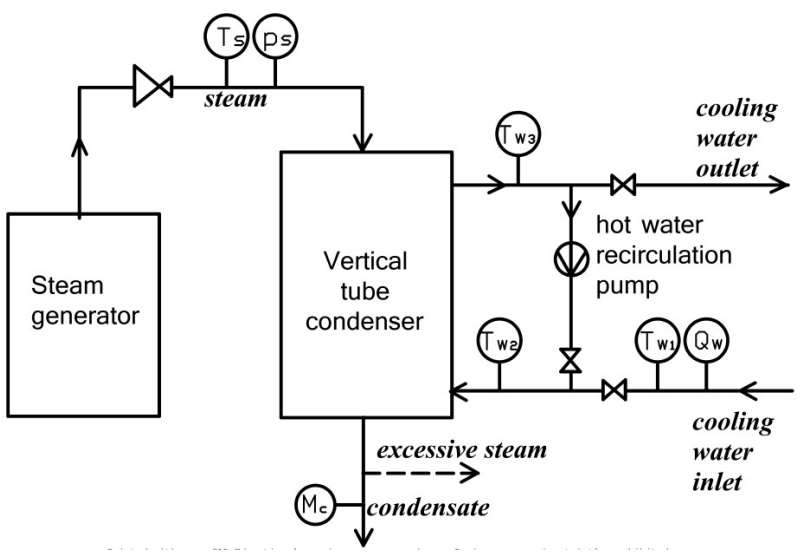

FiguRE 1. Scheme of the testing loop.

\section{EXPERIMENTAL SET-UP}

Experiments for testing and for validating these methods for HTC calculations are carried out on a vertical shell-and-tube heat exchanger, in which the condensing water vapor flows downwards in vertical tubes and the cooling water countercurrent flows in the shell part. The vapor outlet is open to the atmosphere, so the steam condensation pressure is close to atmospheric pressure. The tube bundle is formed by 49 tubes $865 \mathrm{~mm}$ in length, $28 \mathrm{~mm}$ in external diameter and $24 \mathrm{~mm}$ in internal diameter. The tubes are arranged in staggered arrays with a triangular tube pitch of $35 \mathrm{~mm}$. The cross-section of the shell is rectangular in shape, $223 \mathrm{~mm}$ by $270 \mathrm{~mm}$ in size. Seven segmental baffles $(223 \times 230 \mathrm{~mm})$ are used in the shell section, the tube-to-baffle diametral clearance is $1 \mathrm{~mm}$, and there is no shell-to-baffle diametral clearance. The material is stainless steel 1.4301 (AISI 304).

The testing loop is shown in Fig. 1. Steam is produced in a steam generator. Before the steam enters the vertical tube condenser, its parameters are re- duced to the required values. Hot water recirculation enables the cooling water temperature and the cooling water flow rate in the condenser to be regulated. The measured parameters are the inlet cooling water temperature $T_{w 1}$, the temperature of the water after recirculation $T_{w 2}$, the outlet cooling water temperature $T_{w 3}$, the cooling water flow rate $Q_{w}$, the inlet steam pressure $p_{s}$, the inlet steam temperature $T_{s}$ and the amount of steam condensate $M_{c}$.

\subsection{AnAlysis of OVERALl HTC SEnsitivity TO THE SHELL-SIDE AND TUBE-SIDE HTC VALUE}

Determination of the HTC is a complex problem, as there is often a large deviation between theoretical models and experiments. HTC is commonly evaluated with accuracy within $20 \%$ [1, 4. The impact of the tolerance range of the pure steam condensation $\mathrm{HTC} h_{c}$ and the determination of the shell-side HTC $h_{w}$ on the value of the overall HTC is shown in Fig. 2 The overall HTC values are calculated according to (1), where the value of the thermal resistance of the shell-side HTC term $1 / h_{w}$ (see Fig. 3, approximately $10^{-3} \mathrm{~m}^{2} \mathrm{~K} / \mathrm{W}$ ) is significantly higher than the value of the thermal resistance of the condensation HTC term $1 / h_{c}$ (approximately $10^{-4} \mathrm{~m}^{2} \mathrm{~K} / \mathrm{W}[3]$ ).

The sensitivity of the shell-side HTC value to the overall HTC is more significant than the condensation HTC. When calculating the overall HTC, it is of greatest importance to determine the shell-side HTC precisely.

\section{VeRIFying the Shell-Side HTC CALCULATION}

The experiments are carried out on the condenser for the following operating parameters: heat exchanger thermal load, from 20 to $60 \mathrm{~kW}$; logarithmic mean 


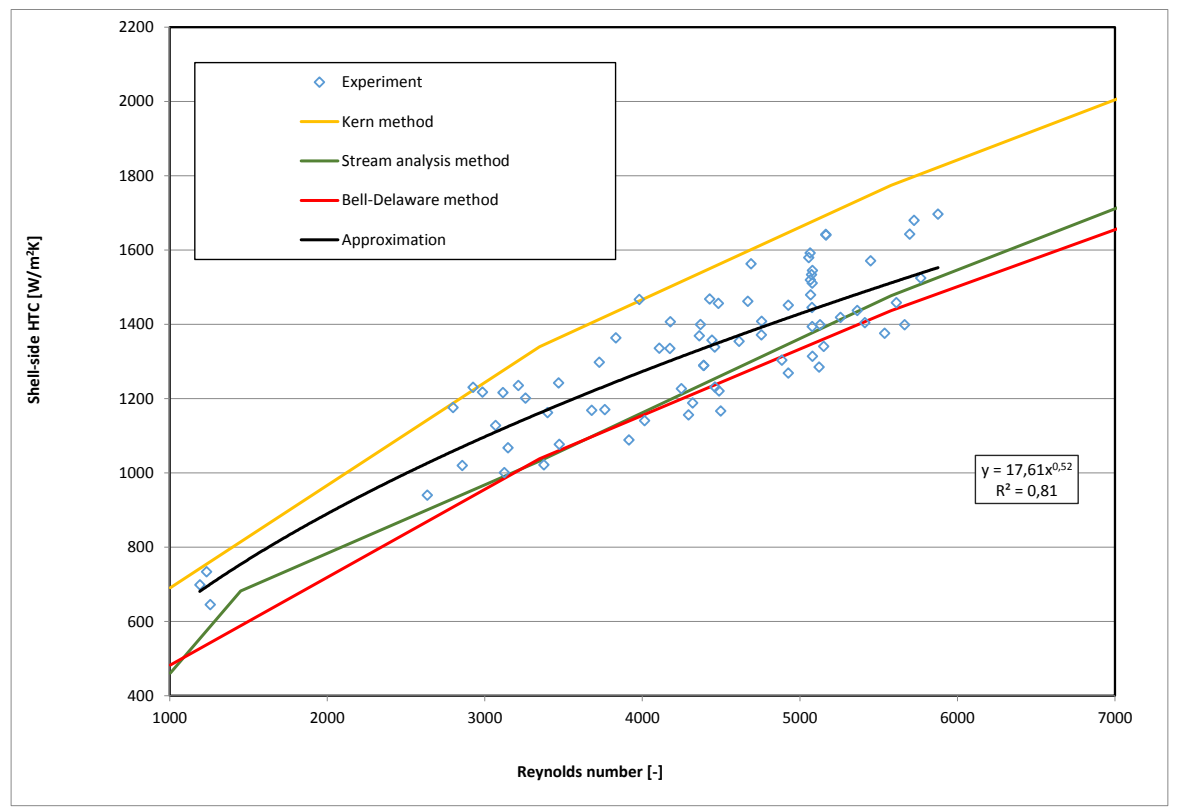

FIGURE 3. Comparison between experimental and theoretical results of the shell-side HTC.

temperature difference, from 6 to $28^{\circ} \mathrm{C}$; and Reynolds number values from 1200 to 6300 (70 measured states). Condensation of saturated pure steam without air is tested. The thickness of the film does not exceed $0.5 \%$ of the value of the tube diameter, so the difference in comparison with a flat plate is negligible. The vapor velocity is up to $1 \mathrm{~m} / \mathrm{s}$, and the maximum value of the Reynolds number of the film does not exceed 100 .

The experimental shell-side HTC values are calculated from the heat balance of the exchanger using measured data to determine the overall HTC. Then the shell-side HTC is calculated from (1), assuming that the results of the Nusselt condensation model for calculating the condensation HTC are valid. The deviation of the measurements ranges from $4 \%$ up to $7 \%$ in dependence on the operating parameters. A comparison between the experimental values and the values determined by the theoretical methods described in Section 4 is shown in Fig. 3 .

The Bell-Delaware method and the Stream-Flow analysis method achieve comparable results, while the results of the Kern method provide significantly higher values. The difference decreases from $40 \%$ for a Reynolds number of 1000 to $21 \%$ for a Reynolds number of 7000. Values for the shell-side HTC calculated from the experimental results lie inside the range marked by the models, and do not correctly match any of them. Our own approximation of the dependence of the shell-side HTC on the Reynolds number is proposed on the basis of experimental results (see Fig. 3), where the Reynolds number is defined according to (4). For the Bell-Delaware method and the Stream- Flow analysis method, the Reynolds number defined in (7) is used in the calculation of HTC, but the Reynolds number used for Fig. 3 is transformed to the value according (4). The change in the Prandtl number for the measurement range is estimated to be within $\pm 3 \%$, so its influence on the change in HTC has been neglected. The proposed approximation

$$
h_{w}=17.61 \mathrm{Re}^{0.52}
$$

is valid for this specific tested condenser for cooling water with a mean temperature about $85^{\circ} \mathrm{C}$ with the coefficient of determination $R^{2}=0.81$.

The total variance in the experimental results is an assumed value, due to the complexity of the heat transfer process and various operating parameters. Fig. 4 compares the overall HTC evaluated from the measured heat balance with the theoretical calculation according the Nusselt theory for calculating the condensation HTC and the approximation of the dependence of the shell-side HTC on the Reynolds number (see Eq. 12). The experimental results match the theoretical results with a range of tolerance mainly within $\pm 10 \%$.

\section{Modifications to the Nusselt THEORY}

The operating conditions of the condenser may differ from the assumptions adopted in the basic Nusselt theory. The following modifications of the Nusselt condensation model, which may occur in the operation of the tested device, are theoretically analyzed:

(1.) Condensation in vertical tubes

(2.) Impact of steam velocity on laminar film flow

(3.) Condensation in the event of turbulent film flow

(4.) Presence of non-condensable gases

\subsection{Condensation in Vertical tubes}

The calculation is similar to the calculation for condensation on a vertical flat wall, assuming that the 


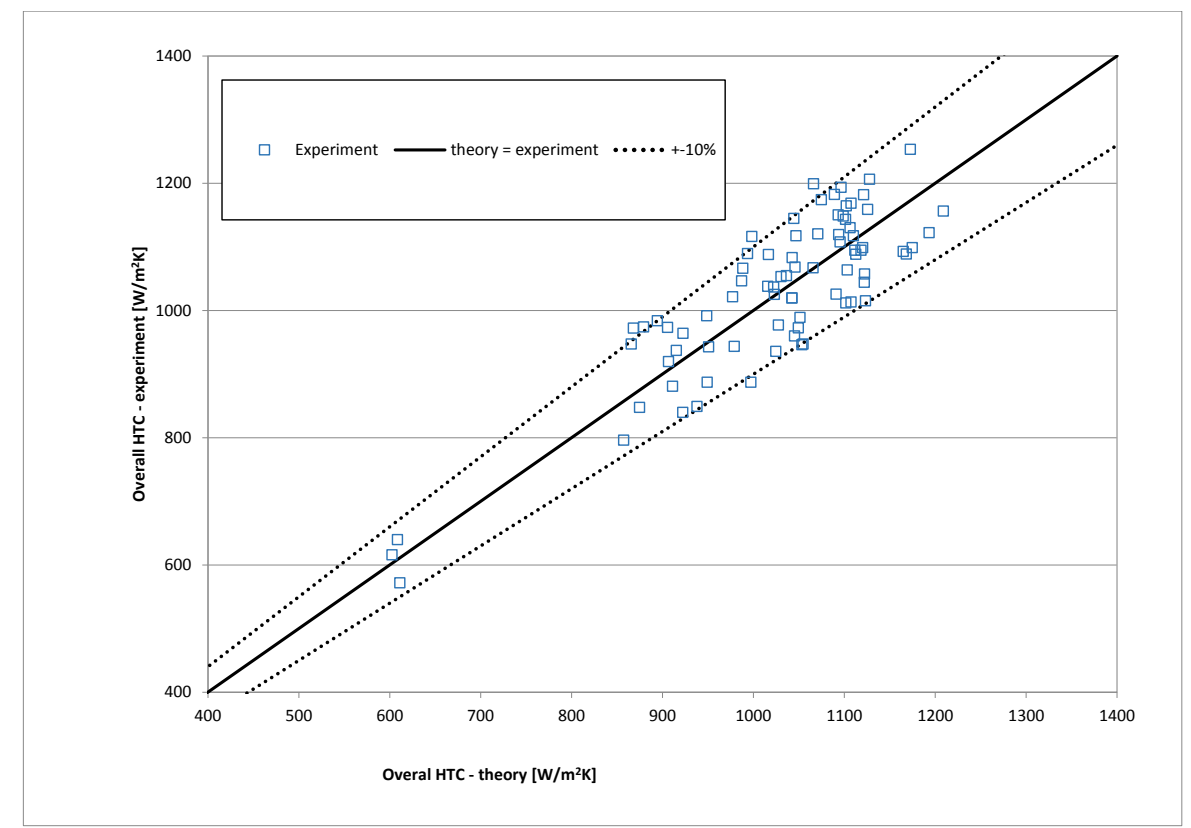

Figure 4. Comparison of the experimental and theoretical results for the overall HTC.

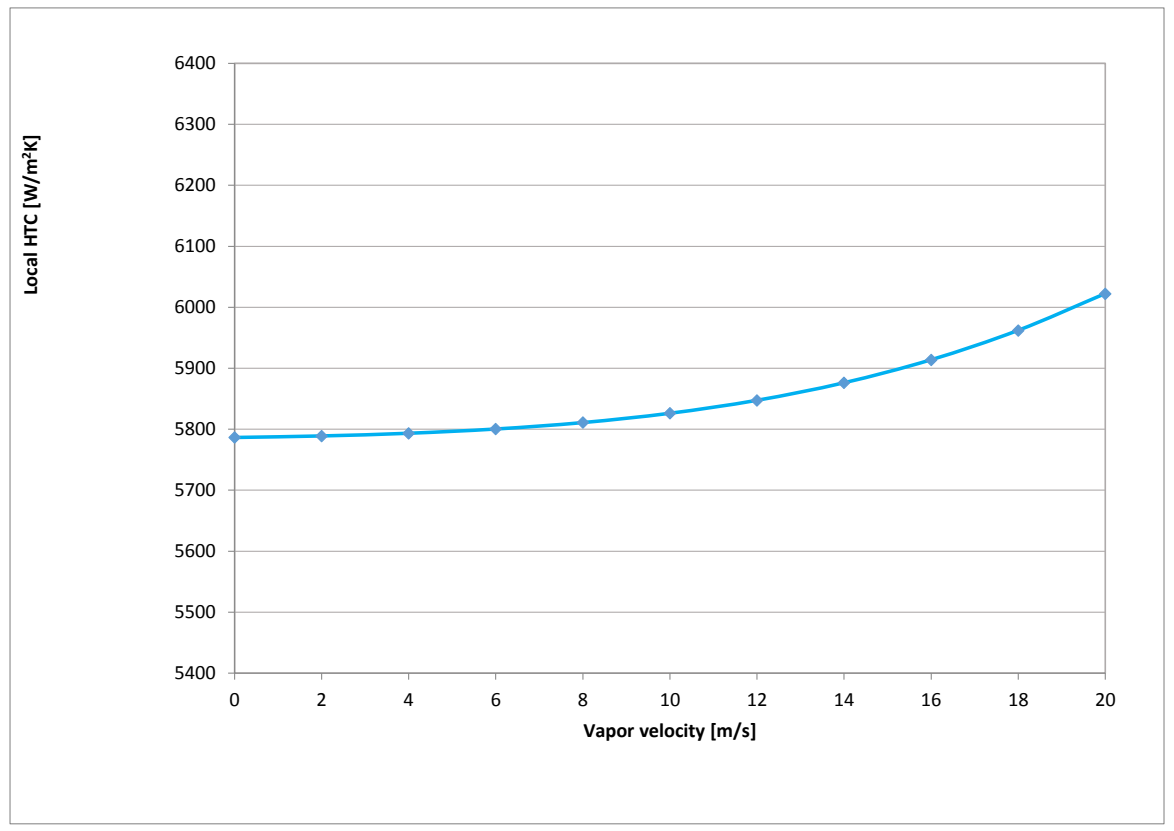

Figure 5. Dependence of the local HTC on steam velocity.

thickness of the film is very small in comparison with the external diameter of the tube [3]. The thickness of the film is evaluated according to the method included in the basic Nusselt theory [2, 3. The maximum value calculated for the operating conditions of the condenser does not exceed $0.5 \%$ of the diameter of the tube. Therefore, the difference in comparison with a flat plate wall is negligible.

\subsection{IMPACT OF STEAM VELOCITY ON LAMINAR FILM FLOW}

During condensation inside vertical tubes, steam works on the surface of the film by a shear force.
When the steam flows downward, the film flow accelerates and the condensation HTC increases slightly. By contrast, when the steam moves upwards, it slows down the film flow [3, 4]. The influence of the steam velocity on the value of the local condensation HTC is evaluated according to the Blangetti method [5]. The results are shown in Fig. 5 The velocity of the steam in the condenser ranges from 1 to $2 \mathrm{~m} / \mathrm{s}$. Therefore, the effect of steam velocity is negligible.

\subsection{Condensation in the CASE OF TURBULENT FILM FLOW}

On the bottom of the high vertical walls or tubes, the thickness of the film can grow to such an extent that 


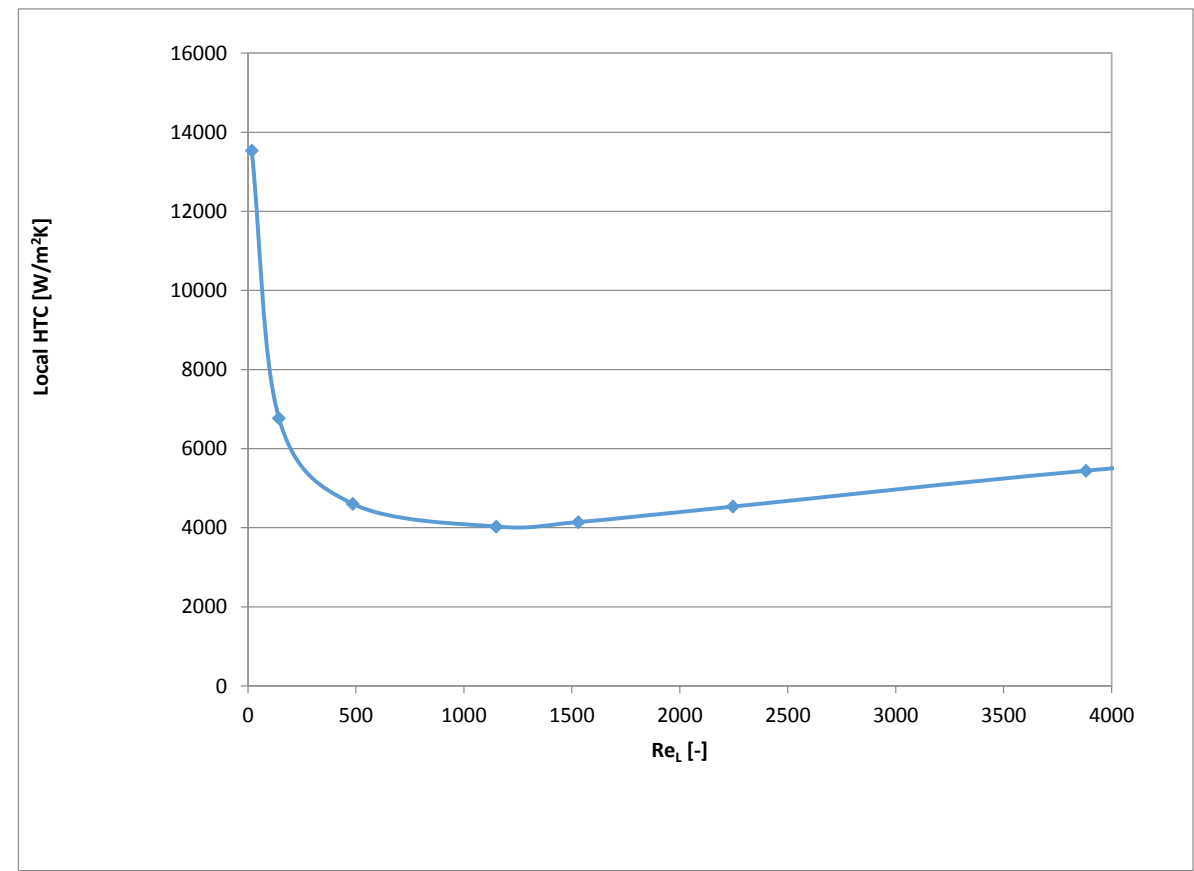

FiguRE 6. Impact of the Reynolds number of the condensate film on HTC.

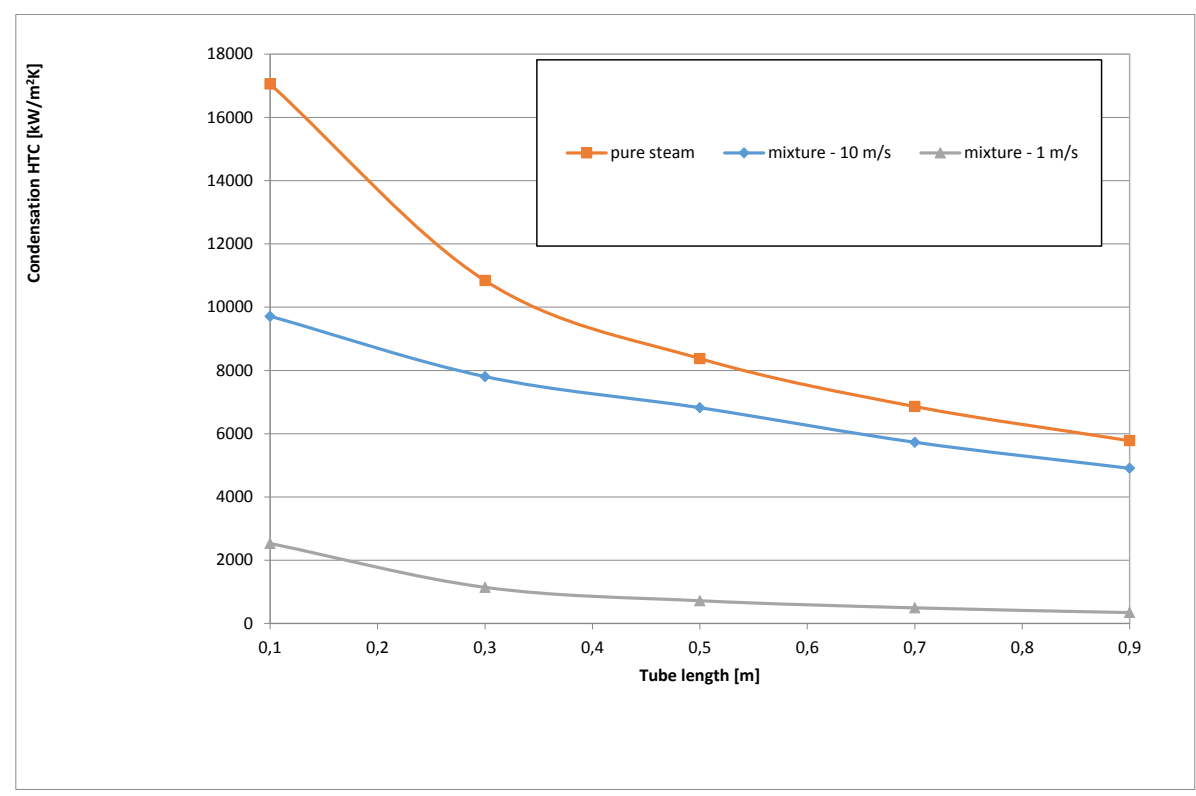

Figure 7. Effect of non-condensable gas on the condensation HTC.

there is a transition to turbulence. This turbulent transport increases the HTC 3, 4. Pure turbulent flow begins when the value of the critical Reynolds number is 1800 [3. The dependence of the Reynolds number of the condensate film on the local condensation HTC is evaluated according to the Blangetti method [5], where the assumption of transition flow is introduced. An increase in the local HTC begins at a Reynolds number value $\operatorname{Re}_{L}$ of 1200 (see Fig. 6). The Reynolds number of the condensate film for the operating conditions of the condenser does not exceed a value of 100 . Therefore, the film flow in the condenser is laminar.

\subsection{PRESENCE OF NON-CONDENSABLE GASES}

If the steam condenses in a mixture with inert gases, the steam molecules diffuse through an inert gas towards the vapor-liquid interface, and this causes a decrease in the partial pressure of the vapor and reduces the HTC. To determine the HTC value, it is necessary to take into account the mass transfer generated by the different partial pressures at the interface between the gas and the liquid phases and the bulk gas [3, 4. In accordance with the analogy between mass transfer and heat transfer, the condensation HTC is evaluated according to the Nusselt model, combined with applying the Dittus-Boelter equation [2] for turbulent flow 


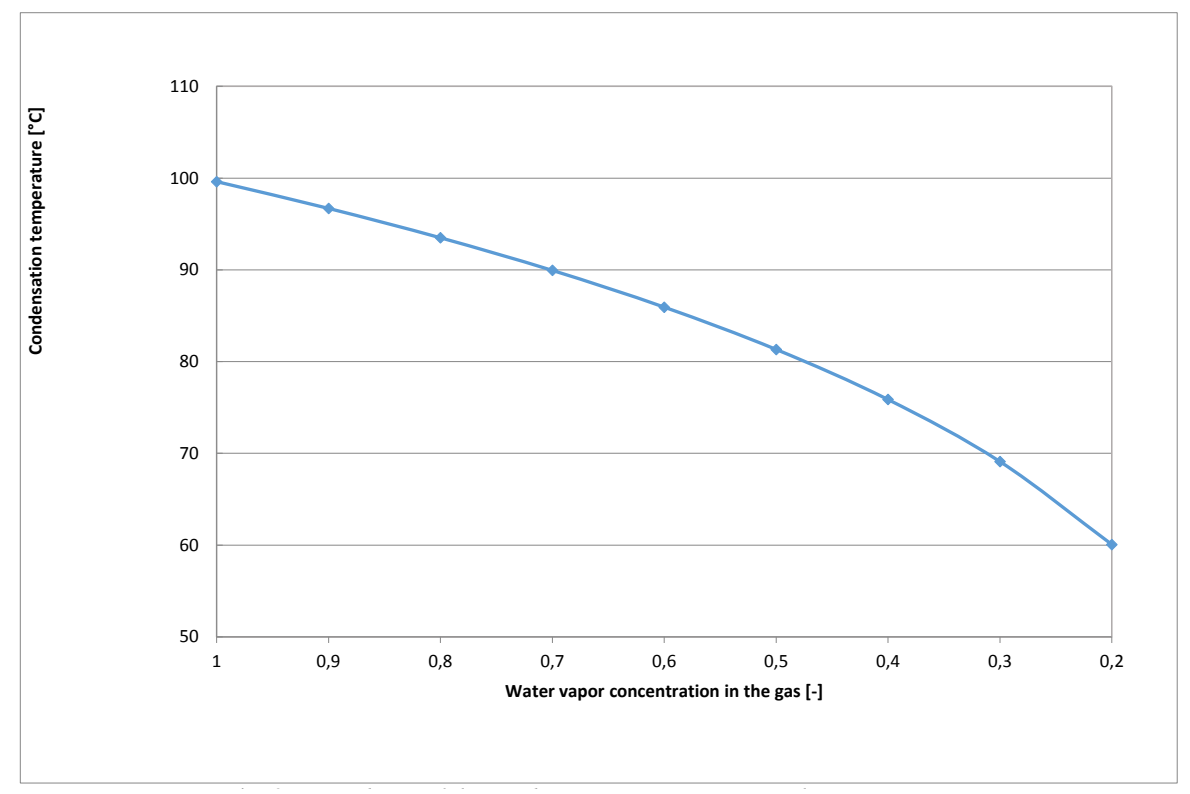

FIGURE 8. Dependence of the condensation temperature on the vapor concentration.

(velocity of $10 \mathrm{~m} / \mathrm{s}$ ) and the Hansen equation 2 (velocity of $1 \mathrm{~m} / \mathrm{s}$ ) for laminar flow in the mass transfer. The results of the calculation for a mixture of steam with $10 \%$ of air are shown in Fig. 7. The value of HTC is significantly affected by the gas velocity. The decrease in the partial pressure also reduces the condensation temperature during the process (see Fig. 8). The impact of the presence of a non-condensable gas on the condensation process in a vertical tube condenser is a subject for further research.

\section{Conclusions}

This paper has dealt with calculating the heat transfer in a vertical tube condenser. We have analyzed the use of the Nusselt model for calculating the condensation HTC inside vertical tubes and the Kern, Bell-Delaware and Stream-flow analysis methods for calculating the shell-side HTC from the tubes to the cooling water. These methods have been verified experimentally for the specific condenser.

The influence of the shell-side HTC on the overall HTC is more significant than the influence of the condensation HTC. Assuming that the Nusselt condensation model is valid, the values of the shell-tube HTC evaluated from the experiments do not correctly match any of the methods mentioned here. We propose our own equation for calculating the dependence of the shell-side HTC on the Reynolds number. The experimentally-determined values of the overall HTC match the results of the proposed theoretical approximation for determining the shell-tube HTC with a range of tolerance mainly within $10 \%$.
A theoretical analysis has been made of the modifications to the Nusselt condensation model that may occur in the operation of the tested device. The effect of steam velocity on a value from 1 to $2 \mathrm{~m} / \mathrm{s}$ is negligible. The thickness of the film does not exceed $0.5 \%$ of the diameter of the tube, so the difference in comparison with a flat plate wall is negligible. The Reynolds number of the condensate film does not exceed a value of 100 . The presence of transition flow and turbulent flow begins at a Reynolds number value of 1200. Therefore, the film flow in the condenser is laminar. The presence of a non-condensable gas reduces the steam condensation temperature and reduces the HTC. This process is significantly affected by the gas velocity. This effect is a topic for further research.

\section{ACKNowledgements}

This work has been supported by the Grant Agency of the Czech Technical University in Prague grant SGS13/134/OHK2/2T/12.

\section{REFERENCES}

[1] G. F. Hewitt, G. L. Shires, T. R. Bott: Process Heat Transfer, Begell house, New York 1994.

[2] F. P. Incropera, D. P. DeWitt: Introduction to heat transfer, Wiley-Academy, New York 1996.

[3] J. Šesták, F. Rieger: Přenos hybnosti, tepla a hmoty. Vydavatelství ČVUT, Praha 1993.

[4] H. D. Bahr, K. Stephan: Heat and mass transfer, Springer, Berlin 1998. DOI: 10.1007/978-3-662-03659-4

[5] F. Blangetti, R. Krebs, E. U. Schünder: Condensation in vertical tubes - Experimental results and modelling. Chemical Engineering Fundamentals 1 (1982) 20-63. 